\title{
Impaired wound healing after neoadjuvant radiotherapy and resection of soft tissue sarcomas
}

\author{
Yasmin Bakhshai \\ University Hospital LMU Munich \\ Alexander Klein \\ University Hospital, LMU Munich \\ Lars Lindner \\ University Hospital, LMU Munich \\ Josefine Rauch \\ University Hospital, LMU Munich \\ Christof Birkenmaier \\ University Hospital, LMU Munich \\ Volkmar Jansson \\ University Hospital, LMU Munich \\ Patrick Weber \\ University Hospital, LMU Munich
}

Hans Roland Dürr ( $\nabla$ hans_roland.duerr@med.uni-muenchen.de )

Ludwig-Maximilians-University Munich https://orcid.org/0000-0002-1347-1173

\section{Research article}

Keywords: Sarcoma, Radiotherapy, Surgery, Wound healing

Posted Date: June 18th, 2020

DOI: https://doi.org/10.21203/rs.3.rs-35653/v1

License: (c) (i) This work is licensed under a Creative Commons Attribution 4.0 International License.

Read Full License 


\section{Abstract \\ Background}

In soft tissue sarcomas (STS) radiotherapy (RTx) may be applied pre- or postoperatively with advantages and disadvantages on either side. We examined the effect of preoperative radiation on wound healing in patients with STS of the extremities and the pelvis.

\section{Methods}

Between August 2008 and March 2011, 32 patients with an average of 54 years (SD 18.7) and with STS (all Grade 2 or 3 ) were treated with a planned wide resection after neoadjuvant RTx leaving a rim of uninvolved soft tissue around the tumor. Preoperative RTx was given at an average dose of 51,5 Gy (SD 4.6) and mean follow up was 12.2 months (SD 9.8). The results were compared to a consecutive series of 60 patients treated later on without neoadjuvant RTx.

\section{Results}

R0 resection were performed in 31 of 32 patients. Impaired wound healing (IWH) occurred in 19 patients (59\%), revision surgery had to be performed in 17 patients (53\% of total). Four patients had to undergo 2 or more revisions. One patient had to be amputated and one patient died due to septic complications after revision surgery. IWH was seen more frequently in the lower (18 / 28) than in the upper extremities (1 / 4), yet this was not statistically significant in our series ( $p=0.223$, Fisher's exact test). Comorbidities were not found to be of influence. In the control group, revision surgery was necessary in $18 \%$ of the patients $(p=0.0006)$.

\section{Conclusions}

Radiotherapy is effective in local tumour control, but causes a high rate of impaired wound healing (59\%), if applied prior to surgery. This frequently resulted in one or more revision surgeries delaying the schedule of further therapies. The authors recommend RTx to be applied only in selected cases in a neoadjuvant setting.

\section{Background}

In the treatment of soft tissue sarcomas (STS) of the extremities limb-sparing surgery is now the standard and amputation is rarely necessary. $[1,2]$ This is achieved mainly by multimodal therapy concepts including the use of chemotherapy (CTx), radiotherapy (RTx) and surgery.[2] There are many approaches to combine the variable options in changing orders with different advantages and disadvantages.[3-6] Neoadjuvant chemotherapy does not have a proven negative effect on wound 
healing in STS, unless surgery is performed during chemotherapy.[7, 8] However, with external beam radiation which may be applied pre- or postoperatively, the timing is still being discussed in the literature. [9-11] In a recent review of 28.000 patients in the US National Cancer Database $51 \%$ of the patients did not receive radiation therapy at all whereas $11.8 \%$ received it preoperatively.[12] The advantage of neoadjuvant radiotherapy is a possible reduction of tumor size, a better definition of the radiation field, thus a lower dose of radiation has to be applied.[1,3,4] This means not only that less tissue has to be exposed to a minor radiation dose, but also that the risks for long term side effects such as lymphedema, scarring or the development of secondary irradiation-induced cancer are lower. $[3,4,13,14]$ But there are negative side effects of preoperative radiation. Disease staging by MRI and in histolopathology is more difficult after irradiation. Surgery in irradiated tissue is challenging due to scars and fibrosis of the tissue. $[13,14]$ Furthermore, wound healing may be disturbed in irradiated tissue, which increases the rate of revision surgery. $[8,13]$ This effect seems to persist even years after the RTx, although the effect diminishes as time goes by.[15]

According to the positive effects described in literature we decided therefore to change our routine postoperative radiation scheme. We saw the benefits of a lower dose of radiation therapy preoperatively. The primary aim of this study was to investigate whether neoadjuvant radiotherapy had an influence on wound healing in a consecutive patient series. The secondary aim was to analyze if postoperative application of brachytherapy had a negative effect on the consolidation of the wound. The third aim was to analyze whether location or size of the lesions had any influence on wound complications and on the outcome. As described further on, we did not expect such a high rate of impaired wound healing thus this treatment regime on a routine basis was stopped and hence the patient series is comparatively small. For comparison a control group with 60 consecutive patients treated later on without neoadjuvant radiotherapy was used.

\section{Patients And Methods}

The study group included patients with high-grade, deep-seated, non-metastatic, STS of the extremities including the pelvis that were assessed to be resectable without amputation. In 32 months, 38 consecutive patients met those criteria. For this study, 5 patients had to be excluded because they did not receive preoperative radiation therapy due to the necessity of immediate surgery. The control group included 60 consecutive patients using the same criteria but without neoadjuvant radiotherapy, treated between 2016 and 2017. In the study group one patient was excluded due to resection 20 months after radiotherapy to obtain a more homogeneous patient group. Thus the study cohort consisted of 32 patients (17 female, 15 male; mean age 54 years, 50 (SD 17.2) years for the women and 57 (SD 21) years for the men) who were scheduled for wide tumor resection. All tumors were classified as Grade 2 or 3 STS. Eight of them had undergone previous surgery at other institutions. Four STS of the upper (UEx) (12.1\%) and 28 tumors of the lower extremities (LEx) including the pelvis (87.9\%) were treated.

In this prospective evaluation the patients were analyzed concerning the clinical, functional and radiological outcomes with special regards to impaired wound healing (IWH) and the need for further 
surgical interventions. Comorbidities known to influence wound healing such as smoking, diabetes and medications with a negative influence on wound healing, such as corticosteroids, etc. were documented.

\section{Neoadjuvant radiotherapy}

All patients received neoadjuvant RTx ( $n=32), 2$ patients also received a second short cycle of boosting external beam radiation postoperatively. Brachytherapy (BTx) was administered in 12 patients. Preoperative RTx was applied at a mean dose of 51.5 Gy (SD 4.6). Adjuvant external beam radiation (boost) was applied at a dose of 16 Gy.

\section{Surgery}

The average delay of surgery was 1.48 months (SD 0.8) after the last application of preoperative radiation therapy. All surgeries were performed by a single, experienced surgeon (HRD). Each surgery was aimed to achieve an R0-resection, even in those patients that had received previous surgery at outside institutions. The latter received a wide excision containing all the potentially contaminated tissue. This series includes 8 pelvic resections including variable amounts of bone in 5 patients. No patient needed a vascular resection with reconstruction. Local flaps (gastrocnemius, fasciocutaneous) had been done primary in some patients, extended local flaps (as rectus abdominis muscle flap) or free vascularized flaps in cases of revision only.

\section{Impaired wound healing}

Wound healing disorders were defined as persistent secretion from the wound, infected or non-infected seroma or hematoma, development of a fistula, infection, failure of a skin flap, wound dehiscence or larger necrosis of wound margins/soft tissue.

\section{Brachytherapy}

When margins were considered marginal during surgery, postoperative application of brachytherapy was planned. Twelve patients had brachytherapy catheters implanted during the index surgery. All those patients had their sarcomas localized in the lower limb, except for one where the diaphysis of the humerus was affected. The mean dose of brachytherapy was $16.5 \mathrm{~Gy}$ (SD 1.6), always applied within the first week after surgery.

\section{Chemotherapy}

Twenty-four patients received CTx. It was administered either only preoperatively $(n=7)$ or pre- and postoperatively $(n=17)$. Neoadjuvant multi-agent therapy consisted mostly of Al (Adriamycin and Ifosfamide; $n=15$ ), EIA (Etoposid, Ifosamid and Adriamycin; $n=8$ ), and other regimens in some instances.[16] Local hyperthermia was added in 21 cases.

\section{Histopathology}


All histopathologic samples of biopsies or resected tumors were reviewed by the same pathologist (TK). The distribution of histotypes is summarized in Table 1.

\section{Endpoint and statistics}

In all patients the appearance and type of IWH, the need for and the extent of further surgeries, local recurrences, the diagnosis of metastatic disease in follow up were documented.

Categorical variables are presented as absolute and relative frequencies, while continuous variables are presented as mean and standard deviation (SD). For between-group comparisons, two-tailed Student's ttests or Mann-Whitney U tests were applied, as considered appropriate. Chi square or Fisher's exact tests were performed to determine the significance of differences in proportions. Tests were two-tailed with Pvalues of .05 or less considered to be statistically significant. A multiple logistic regression was performed to adjust for several confounding factors. The data analysis software used was MedCalc®.

\section{Results}

The mean follow-up period was 12.2 months (SD 9.8) after surgery. We saw impaired wound healing in 19 patients $(59,4 \%)$. The complications mostly seen were failure of wound closure, prolonged secretion and necrosis of either the wound margins or the surrounding soft tissues (see Table 2).

Revision surgery had to be performed in 17 of those patients ( $90 \%$ of all IWH, $53 \%$ of all patients), 4 patients ( $21 \%$ of IWH, $13 \%$ of total) had to undergo 2 or more revisions in order to accomplish wound healing. One patient had to be amputated in the course of therapy, one died due to septic complications (infected central venous catheter) after revision surgery, one patient died from progressive disease (coexisting multiple myeloma).

Of the patient cohort only one had a history of smoking, two had diabetes and one of these diabetics also had a corticosteroid medication due to lung disease. None of those 3 patients developed a wound healing disorder.

Of the 17 patients requiring revision surgery due to IWH, 12 (70.6\%) had received neoadjuvant CTx and RTx, five (29.4\%) had received only neoadjuvant RTx. In those patients not needing revision surgery, 12 $(80 \%)$ had received neoadjuvant CTx and RTx and $3(20 \%)$ had received RTx only $(p=0,475)$.

The mean maximum diameter of the tumor prior to surgery was $10.8 \mathrm{~cm}(S D=6.9)$. Seven $(21.9 \%)$ of the 32 tumors were smaller than $5 \mathrm{~cm}, 25$ (78.1\%) were larger. Four (57\%) of the seven patients with tumors smaller than $5 \mathrm{~cm}$ had revisions. Thirteen (52\%) of the 25 patients with tumors larger than $5 \mathrm{~cm}$ needed further surgery. As assessed by use of the T-test, tumor size in patients with IWH was not significantly different from those without IWH $(p=0.821)$.

Twelve patients $(37,5 \%)$ underwent afterloading therapy in the week after surgery. This did not have an influence with regards to wound healing $(50 \%$ had IWH, all of those needed further surgery, $50 \%$ did not 
develop IWH). With the combination of neoadjuvant CTx and RTx and postoperative BTx $(n=10), 5$ patients ( $50 \%$ of the afterloading group) needed secondary surgery for wound healing problems and one of those had to be amputated.

\section{Tumor Location}

$\mathrm{R} 0$ resection was achieved in 31 of 32 patients whereas in one patient histopathology proved an R1resection (patient in Fig. 1). This patient with an R1 resection had neoadjuvant CTx and RTx as well as adjuvant BTx. Postoperative CTx had to be stopped due to IWH. Eight revision surgeries including two free flaps finally resulted in an amputation at the level of the proximal thigh (no remaining tumor).

We saw IWH in only one (25\%) of the patients who had a STS of the upper extremity, whereas 18 (64.3\%) of the 28 patients with lower extremity STS developed IWH. The tumors located at the upper extremity had an average size of $4.8 \mathrm{~cm}$ (SD 2.97) and the tumors at the lower extremity showed an average diameter of $11.7 \mathrm{~cm}$ (SD 6.9). Tumors at the lower extremity were significantly larger than those of the upper extremity ( $p=0.006$, t-test). Yet, when analyzed using Fisher's Exact Test, there was no significant association between tumor location and IWH $(p=0.223)$.

At the latest follow-up only one patient showed local recurrence. This patient presented at our institution after previous surgery elsewhere where the tumor had been resected with an R1 margin. This patient underwent CTx and RTx and then a second resection (RO) at our institution. One year later the patient required resection of a local recurrence and developed metastatic disease.

\section{Comparison to control group}

The clinical data of the control group in comparison to the study group is described in Table 3. Mean age was about 10 years older and the rate of chemotherapy about half as high as in the study group. Revision rate was found to be significantly lower ( $18 \%$ vs. $53 \%)$. Including only patients with chemotherapy the same lower rate of revision surgery ( $21 \%$ vs $50 \%)$ could be proven.

\section{Discussion}

This study showed a high rate (59.4\%) of IWH with preoperative RTx in STS. Application of brachytherapy had no additional negative influence on wound healing. As to whether radiotherapy should be applied preor postoperatively, the current opinion in the literature differs. Some studies claim that there is a slight benefit regarding local control with neoadjuvant RTx, others have found no difference. $[6,17,18]$ Regarding the 5-year overall survival rate, a similar discussion exists. $[3,6,10,18]$ In recent years the use of preoperative RTx increased in the US from $16.8 \%$ in 2004 to $29.7 \%$ in 2012.[19] Due to a lower incidence of chronic adverse effects with RTx in the preoperative setting, neoadjuvant RTx also seems to be more cost effective. [20]

While the timing of RTx most likely has a minimal (if at all) effect on local control and overall survival, it is essential with regards to wound healing, functional outcome and most important on starting any 
postoperative sarcoma therapy. It is less likely that a patient irradiated after surgery will display severe wound healing impairment. $[13,21]$

Wound healing problems appear in irradiated tissue whether applied in single or multiple fractions. $[5,13$, 21] Table 3 shows the probabilities of wound complications in regards to the timing of RTx in several other studies.[1, 3, 11, 22-24]

This adverse effect is, among other factors, caused by an alteration of the fibroblasts which produce collagen. RTx also causes changes in the basal membranes and increases vascular permeability stimulating swelling, stasis, thrombosis and probably also a reduction in neovascularisation.[25]

We found a high rate (59.4\%) of impaired wound healing in our patients with $53 \%$ having to undergo revision surgery for this reason. $13 \%$ underwent two or more revisions in order to achieve wound healing. One patient even died due to septic complications after revision surgery and one had to be amputated. These numbers compare to other studies that showed up to $67 \%$ for acute wound complications after surgery in irradiated tissue, $[3,23,26,27]$ rates of revision surgeries in those patients were up to $45 \%$.[3]

In keeping with the results of other studies we saw that patients with tumors in the upper extremity suffered from less wound healing disorders with a resulting need for further surgery than those with tumors in the lower extremity,[2; 10;11;39] although this was not statistically significant in our series, most probably due to the small number of patients with STS at the upper extremity. One of the main reasons for this is claimed to be the bigger size of the tumors in the lower extremity by the time of presenting for surgery. Delayed wound healing is also considered to be more frequent at the lower limbs, because lower limbs are more prone to blood flow disorders. The difference in size could be seen in our patient collective as well. The tumors in the lower extremities were at an average more than twice the size of the tumors in the upper extremities and this was statistically significant. Bigger tumors come along with a larger defect after surgery which is more likely to develop wound healing disorders even though the surgeon always tries to fill in or cover all soft tissue defects. We could not prove that but think this may be caused by the small number of low sized tumors in this study. It is common sense, but in irradiated STS of most importance, that all wounds should be closed without tension and drained to prevent seroma or haematoma formation which further increase the risk of local wound problems. Investigating routine plastic surgery involvement in managing sarcomas a decrease in the incidence of infectious complications requiring IV antibiotics by about $20 \%$ and a reduction of skin graft losses of $75 \%$ were observed in one study and a reduced rate of IWH from $67-37 \%$ in another.[26, 28] So this might also explain our own worse results without routine involvement of plastic surgery. Microvascular flap reconstructions do not have a higher complication rate in pre-irradiated vs non-irradiated patients. [29] But in the same study from Toronto the rate of recipient site wound healing complications was also $50 \%$ vs $14 \%$. Some surgeons keep skin sutures in STS longer than otherwise usual, even up to one month.[13] Complications especially within the first two weeks should lead to early revision, later and minor complications may be observed or treated by minor intervention leading to secondary wound healing.[13, 30] 


\section{Limitations Of The Study}

A limitation of this study is the non-randomized control group. Based on the literature we decided to change our routine postoperative radiation scheme. We saw the benefits of a lower dose of radiation therapy preoperatively, resulting in a smaller risk for negative long-term effects and better functional outcome due to reduced edema and scarring. We did not expect such a high rate of IWH. In our opinion, this rate was inacceptable high and delayed subsequent sarcoma therapy (i.e. postoperative CTx). This alone has led us to the conclusion to change our regime and to apply RTx routinely postoperatively again with an exception for those patients who have a myxoid sarcoma or a very close proximity to critical structures.

\section{Conclusions}

Radiotherapy is an effective tool in the therapy of soft tissue sarcomas. Since the oncological effect of timing is mainly unclear or -if present- minor, the decision which application schedule is chosen depends on the long-term functional benefit from less applied radiation dose standing against wound healing impairments. Especially when the tumor is large, located in the lower extremity and in a critical anatomical location, wound healing disorders are more likely to occur. In this study, adjuvant CTx was also postponed or had to be diminished in many cases due to long lasting wound healing disorders. Hence we no longer perform preoperative RTx as a standard in STS but decide timing of radiation individually. Patients with myxoid tumors, responding well to RTx, or tumors with close contact to critical structures as nerves, vessels or the bone are still treated preoperative. Routine plastic surgery involvement in planning sarcoma resection must be considered to decrease complications after neoadjuvant RTx.

\section{Abbreviations}

BTx: brachytherapy; CTx:chemotherapy; G1, G2, G3:Grading according to the French Federation of Cancer Centers grading system; Gy:Gray; IWH:impaired wound healing; Lex:lower extremities; MRI:Magnetic resonance imaging; n.s.:not significant; R0, R1, R2:resection margin; RTx:radiotherapy; SD:standard deviation; STS:soft tissue sarcomas; UEx:upper extremities;

\section{Declarations}

\section{Conflict of interest statement}

All authors have no financial and personal relationships with other people or organizations that could inappropriately influence (bias) this work. This study was not supported by any grants or funding despite the academic setting of the institutions and authors.

\section{Ethics approval and consent to participate}


This study was approved by the ethics committee of the Medical Faculty, University of Munich. Written consent was obtained from all the patients included in this study.

\section{Consent for publication}

Not applicable.

\section{Availability of data and materials}

The datasets used and/or analyzed during the current study are available from the corresponding author on reasonable request.

\section{Competing interests}

The authors declare that they have no competing interests.

\section{Funding}

This study did not have any grants or funding despite the academic setting of the institutions and authors.

\section{Acknowledgements}

Not applicable.

\section{Authors' contributions}

Y.B.

Contacted the patients and acquired the data, involved in drafting and revising of the manuscript.

A.K.

Assistant surgeon on many of the cases, involved in drafting and revising of the manuscript.

\section{L.L.}

Oncologist. None of the patients in the study received chemotherapy. But every patient was discussed in the interdisciplinary panel and the decision not to treat was based on this, involved in drafting and revising of the manuscript.

\section{J.R.}

Reviewing the radiotherapy and deciding which patient to treat or not to treat, involved in drafting and revising of the manuscript.

C.B. 
Assistant surgeon on many of the cases, reviewer of the manuscript, involved in drafting and revising of the manuscript.

P.W.

Assistant surgeon on many of the cases, involved in drafting and revising of the manuscript.

V.J.

Assistant surgeon on many of the cases, reviewer of the manuscript, involved in drafting and revising of the manuscript.

H.R.D.

\section{Corresponding author}

Developed the study concept, did the final data analysis and provided the major clinical input in writing and revising of the manuscript. Attending surgeon specialized in Orthopedic Oncology.

Each author has contributed significantly to, and is willing to take public responsibility for this study: its design, data acquisition, and analysis and interpretation of data. All authors have been actively involved in the drafting and critical revision of the manuscript.

\section{References}

1. Virkus WW, Mollabashy A, Reith JD, Zlotecki RA, Berrey BH, Scarborough MT. Preoperative radiotherapy in the treatment of soft tissue sarcomas. Clinical orthopaedics and related research 2002(397):177-189.

2. Casali PG, Abecassis N, Bauer S, Biagini R, Bielack S, Bonvalot S, Boukovinas I, Bovee J, Brodowicz T, Broto JM, et al: Soft tissue and visceral sarcomas: ESMO-EURACAN Clinical Practice Guidelines for diagnosis, treatment and follow-up. Ann Oncol 2018.

3. O'Sullivan B, Davis AM, Turcotte R, Bell R, Catton C, Chabot P, Wunder J, Kandel R, Goddard K, Sadura $A$, et al. Preoperative versus postoperative radiotherapy in soft-tissue sarcoma of the limbs: a randomised trial. Lancet. 2002;359(9325):2235-41.

4. Pollack A, Zagars GK, Goswitz MS, Pollock RA, Feig BW, Pisters PW. Preoperative vs. postoperative radiotherapy in the treatment of soft tissue sarcomas: a matter of presentation. Int J Radiat Oncol Biol Phys. 1998;42(3):563-72.

5. Jeys LM, Luscombe JS, Grimer RJ, Abudu A, Tillman RM, Carter SR. The risks and benefits of radiotherapy with massive endoprosthetic replacement. The Journal of bone joint surgery British volume. 2007;89(10):1352-5.

6. Cheng EY, Dusenbery KE, Winters MR, Thompson RC. Soft tissue sarcomas: preoperative versus postoperative radiotherapy. Journal of surgical oncology. 1996;61(2):90-9. 
7. Stadelmann WK, Digenis AG, Tobin GR: Impediments to wound healing. American journal of surgery 1998, 176(2A Suppl):39 s-47 s.

8. Payne WG, Naidu DK, Wheeler CK, Barkoe D, Mentis M, Salas RE, Smith DJ Jr, Robson MC. Wound healing in patients with cancer. Eplasty. 2008;8:e9.

9. Haas RL, Delaney TF, O'Sullivan B, Keus RB, Le Pechoux C, Olmi P, Poulsen JP, Seddon B, Wang D, Sampath S, et al. Radiotherapy for management of extremity soft tissue sarcomas: why, when, and where? Int J Radiat Oncol Biol Phys. 2012;84(3):572-80.

10. Sampath S, Schultheiss TE, Hitchcock YJ, Randall RL, Shrieve DC, Wong JY. Preoperative versus postoperative radiotherapy in soft-tissue sarcoma: multi-institutional analysis of 821 patients. Int $\mathrm{J}$ Radiat Oncol Biol Phys. 2011;81(2):498-505.

11. Curtis KK, Ashman JB, Beauchamp CP, Schwartz AJ, Callister MD, Dueck AC, Gunderson LL, Fitch TR. Neoadjuvant chemoradiation compared to neoadjuvant radiation alone and surgery alone for Stage II and III soft tissue sarcoma of the extremities. Radiation oncology (London England). 2011;6:91.

12. Gingrich AA, Bateni SB, Monjazeb AM, Darrow MA, Thorpe SW, Kirane AR, Bold RJ, Canter RJ. Neoadjuvant Radiotherapy is Associated with R0 Resection and Improved Survival for Patients with Extremity Soft Tissue Sarcoma Undergoing Surgery: A National Cancer Database Analysis. Ann Surg Oncol. 2017;24(11):3252-63.

13. Tibbs MK, Suit HD, Spiro I, Wolfson AH, Springfield DS, Issels RD, Lindner LH, Verweij J, Wust $P$, Reichardt $P$, et al. Wound healing following radiation therapy: a review. Radiother Oncol. 1997;42(2):99-106.

14. Wolfson AH. Preoperative vs postoperative radiation therapy for extremity soft tissue sarcoma: controversy and present management. Current opinion in oncology. 2005;17(4):357-60.

15. Springfield DS. Surgical wound healing. Cancer treatment research. 1993;67:81-98.

16. Issels RD, Lindner LH, Verweij J, Wust P, Reichardt P, Schem BC, Abdel-Rahman S, Daugaard S, Salat $\mathrm{C}$, Wendtner $\mathrm{CM}$, et al. Neo-adjuvant chemotherapy alone or with regional hyperthermia for localised high-risk soft-tissue sarcoma: a randomised phase 3 multicentre study. The Lancet Oncology. 2010;11(6):561-70.

17. Al-Absi E, Farrokhyar F, Sharma R, Whelan K, Corbett T, Patel M, Ghert M, Davis AM, O'Sullivan B, Turcotte $\mathrm{R}$, et al. A systematic review and meta-analysis of oncologic outcomes of pre- versus postoperative radiation in localized resectable soft-tissue sarcoma. Ann Surg Oncol. 2010;17(5):1367-74.

18. Davis AM, O'Sullivan B, Turcotte R, Bell R, Catton C, Chabot P, Wunder J, Hammond A, Benk V, Kandel $R$, et al. Late radiation morbidity following randomization to preoperative versus postoperative radiotherapy in extremity soft tissue sarcoma. Radiother Oncol. 2005;75(1):48-53.

19. Lazarev S, McGee H, Moshier E, Ru M, Demicco EG, Gupta V, Qu XM, Louie AV, Ashman J, Wasif N, et al. Preoperative vs postoperative radiation therapy in localized soft tissue sarcoma: Nationwide patterns of care and trends in utilization. Pract Radiat Oncol. 2017;7(6):e507-16. 
20. Qu XM, Louie AV, Ashman J, Wasif N. Cost-Effectiveness Analysis of Preoperative Versus Postoperative Radiation Therapy in Extremity Soft Tissue Sarcoma. Int J Radiat Oncol Biol Phys. 2017;97(2):339-46.

21. Davis AM, O'Sullivan B, Bell RS, Turcotte R, Catton CN, Wunder JS, Chabot P, Hammond A, Benk V, Isler $\mathrm{M}$, et al. Function and health status outcomes in a randomized trial comparing preoperative and postoperative radiotherapy in extremity soft tissue sarcoma. Journal of clinical oncology: official journal of the American Society of Clinical Oncology. 2002;20(22):4472-7.

22. McGee L, Indelicato DJ, Dagan R, Morris CG, Knapik JA, Reith JD, Scarborough MT, Gibbs CP, Marcus RB Jr, Zlotecki RA. Long-term results following postoperative radiotherapy for soft tissue sarcomas of the extremity. Int J Radiat Oncol Biol Phys. 2012;84(4):1003-9.

23. Tseng JF, Ballo MT, Langstein HN, Wayne JD, Cormier JN, Hunt KK, Feig BW, Yasko AW, Lewis VO, Lin $\mathrm{PP}$, et al. The effect of preoperative radiotherapy and reconstructive surgery on wound complications after resection of extremity soft-tissue sarcomas. Ann Surg Oncol. 2006;13(9):1209-15.

24. Cannon CP, Ballo MT, Zagars GK, Mirza AN, Lin PP, Lewis VO, Yasko AW, Benjamin RS, Pisters PW. Complications of combined modality treatment of primary lower extremity soft-tissue sarcomas. Cancer. 2006;107(10):2455-61.

25. Gieringer M, Gosepath J, Naim R. Radiotherapy and wound healing: principles, management and prospects (review). Oncol Rep. 2011;26(2):299-307.

26. Barwick WJ, Goldberg JA, Scully SP, Harrelson JM. Vascularized tissue transfer for closure of irradiated wounds after soft tissue sarcoma resection. Annals of surgery. 1992;216(5):591-5.

27. Kunisada T, Ngan SY, Powell G, Choong PF. Wound complications following pre-operative radiotherapy for soft tissue sarcoma. Eur J Surg Oncol. 2002;28(1):75-9.

28. Agrawal N, Wan D, Bryan Z, Boehmler J, Miller M, Tiwari P. Outcomes analysis of the role of plastic surgery in extremity sarcoma treatment. J Reconstr Microsurg. 2013;29(2):107-11.

29. Townley WA, Mah E, O'Neill AC, Wunder JS, Ferguson PC, Zhong T, Hofer SO. Reconstruction of sarcoma defects following pre-operative radiation: free tissue transfer is safe and reliable. J Plast Reconstr Aesthet Surg. 2013;66(11):1575-9.

30. Livi L, Santoni R, Paiar F, Bastiani P, Beltrami G, Caldora P, Capanna R, De Biase P, Detti B, Fondelli S, et al. Late treatment-related complications in 214 patients with extremity soft-tissue sarcoma treated by surgery and postoperative radiation therapy. American journal of surgery. 2006;191(2):230-4.

31. Rosenberg LA, Esther RJ, Erfanian K, Green R, Kim HJ, Sweeting R, Tepper JE. Wound complications in preoperatively irradiated soft-tissue sarcomas of the extremities. Int J Radiat Oncol Biol Phys. 2013;85(2):432-7.

32. O'Sullivan B, Griffin AM, Dickie Cl, Sharpe MB, Chung PW, Catton CN, Ferguson PC, Wunder JS, Deheshi BM, White LM, et al. Phase 2 study of preoperative image-guided intensity-modulated radiation therapy to reduce wound and combined modality morbidities in lower extremity soft tissue sarcoma. Cancer. 2013;119(10):1878-84. 
33. Griffin AM, Dickie Cl, Catton CN, Chung PW, Ferguson PC, Wunder JS, O'Sullivan B. The influence of time interval between preoperative radiation and surgical resection on the development of wound healing complications in extremity soft tissue sarcoma. Ann Surg Oncol. 2015;22(9):2824-30.

34. Lehane C, Ho F, Thompson SR, Links D, Lewis C, Smee R, Parasyn A, Friedlander M, Williams J, Crowe P. Neoadjuvant chemoradiation (modified Eilber protocol) versus adjuvant radiotherapy in the treatment of extremity soft tissue sarcoma. J Med Imaging Radiat Oncol. 2016;60(4):539-44.

35. Nystrom LM, Miller BJ. Transcutaneous Oximetry May Predict Wound Healing Complications In Preoperatively Radiated Soft Tissue Sarcoma. lowa Orthop J. 2016;36:117-22.

36. LeBrun DG, Guttmann DM, Shabason JE, Levin WP, Kovach SJ, Weber KL. Predictors of Wound Complications following Radiation and Surgical Resection of Soft Tissue Sarcomas. Sarcoma. 2017;2017:5465130.

37. Chan LWM, Imanishi J, Grinsell DG, Choong P. Preoperative Radiotherapy and Wide Resection for Soft Tissue Sarcomas: Achieving a Low Rate of Major Wound Complications with the Use of Flaps. Results of a Single Surgical Team. Front Surg. 2017;4:79.

38. Stevenson MG, Ubbels JF, Slump J, Huijing MA, Bastiaannet E, Pras E, Hoekstra HJ, Been LB. Identification of predictors for wound complications following preoperative or postoperative radiotherapy in extremity soft tissue sarcoma. Eur J Surg Oncol 2018.

39. Bedi M, King DM, DeVries J, Hackbarth DA, Neilson JC. Does Vacuum-assisted Closure Reduce the Risk of Wound Complications in Patients With Lower Extremity Sarcomas Treated With Preoperative Radiation? Clin Orthop Relat Res. 2019;477(4):768-74.

40. Lansu J, Groenewegen J, van Coevorden F, van Houdt W, van Akkooi ACJ, van Boven H, van de Sande M, Verheij M, Haas RL. Time dependent dynamics of wound complications after preoperative radiotherapy in Extremity Soft Tissue Sarcomas. Eur J Surg Oncol. 2019;45(4):684-90.

\section{Tables}

TABLE 1: Distribution of histiotypes 


\begin{tabular}{|ll|}
\hline Entities (all G 2/3) & $\mathbf{n}$ \\
\hline NOS (none otherwise specified) & 12 \\
\hline Synovial sarcoma & 5 \\
\hline Leiomyosarcoma & 3 \\
\hline Fibrosarcoma & 2 \\
\hline Malign. peripheral nerve sheat tumour & 2 \\
\hline Liposarcoma & 2 \\
\hline Epitheloid sarcoma & 2 \\
\hline Angiosarcoma & 1 \\
\hline Malignant giant cell tumour & 1 \\
\hline Undifferentiated pleomorphic sarcoma & 1 \\
\hline Haemangiosarcoma & 1 \\
\hline
\end{tabular}

TABLE 2: Detailed analysis of wound healing disorders (multiple naming possible)

\begin{tabular}{|ll|}
\hline Wound healing disorders & $\mathbf{n}$ \\
\hline Failure of wound closure & 6 \\
\hline Secretion & 6 \\
\hline Necrosis of the wound margins/soft tissues & 5 \\
\hline Deep wound infection & 4 \\
\hline Seroma (non-/infected) & 4 \\
\hline Necrosis of flap & 2 \\
\hline Fistula & 3 \\
\hline Infected haematoma & 1 \\
\hline
\end{tabular}

TABLE 3: Clinical data of study and control group 


\begin{tabular}{|llll|}
\hline Parameter & Study group & Control & P \\
\hline Male / Female & $15 / 17$ & $35 / 25$ & n.s. \\
\hline Mean age (years) & $54($ SD 17.2) & $63($ SD 18.2) & 0.0268 \\
\hline Upper / Lower extremity & $4(12 \%) / 28$ & $17(28 \%) / 43$ & n.s. \\
\hline Chemotherapy (CTX) before surgery & $24(75 \%)$ & $21(35 \%)$ & 0.0003 \\
\hline Surgical Margins (R0/R1) & $31 / 1(3 \%)$ & $53 / 7(12 \%)$ & n.s. \\
\hline Largest diameter (cm) & $10.8($ SD 6.9) & $8.0($ SD 7.0) & n.s. \\
\hline Mean follow-up (months) & $12.2($ SD 9.8$)$ & $17.2($ SD 9.9) & n.s. \\
\hline Impaired wound healing (IWH) & $19(59 \%)$ & $17(28 \%)$ & 0.0037 \\
\hline Revision surgery (RS) & $17(53 \%)$ & $11(18 \%)$ & 0.0006 \\
\hline Revisions in patients with CTX & $12(50 \%)$ & $3(21 \%)$ & 0.0112 \\
\hline
\end{tabular}

TABLE 4: Probability of IWH depending on timing of RTX 


\begin{tabular}{|lllllll|}
\hline & & & \multicolumn{2}{l}{ Preoperative RTx } & \multicolumn{2}{l|}{ Postoperative RTx } \\
\hline Study & Year & Patients (n) & Dose (Gy) & IWH (\%) & Dose (Gy) & IWH (\%) \\
\hline Barwick [26] & 1992 & 37 & 52 & 51 & - & - \\
\hline Virkus [1] & 2002 & 209 & 50.4 & 22 & - & - \\
\hline Kunisada [27] & 2002 & 43 & 50.4 & 44 & & \\
\hline O'Sullivan [3] & 2002 & 182 & 50 & 35 & 66 & 17 \\
\hline Cannon [24] & 2006 & 412 & 50 & 34 & 60 & 16 \\
\hline Tseng [23] & 2006 & 173 & 50 & 32 & - & - \\
\hline Curtis [11] & 2011 & 36 & 50.4 & 42 & - & - \\
\hline McGee [22] & 2012 & 173 & - & - & 65 & 3.4 \\
\hline Rosenberg [31] & 2013 & 73 & 50 & 32 & - & - \\
\hline O'Sullivan [32] & 2013 & 59 & 50 & 31 & - & - \\
\hline Griffin [33] & 2015 & 798 & 50 & 23 & - & - \\
\hline Lehane [34] & 2016 & 63 & 30 & 14 & $60-66$ & 12 \\
\hline Nystrom [35] & 2016 & 10 & 50 & 40 & - & - \\
\hline LeBrun [36] & 2017 & 67 & 50 & 32 & 50 & 40 \\
\hline Chan [37] & 2017 & 117 & 50 & 26 & - & - \\
\hline Stevenson [38] & 2018 & 127 & 50 & 40 & 60 & 20 \\
\hline Bedi [39] & 2019 & 84 & 50 & 47 & - & - \\
\hline Lansu [40] & 2019 & 191 & 50 & 31 & - & - \\
\hline
\end{tabular}

\section{Figures}




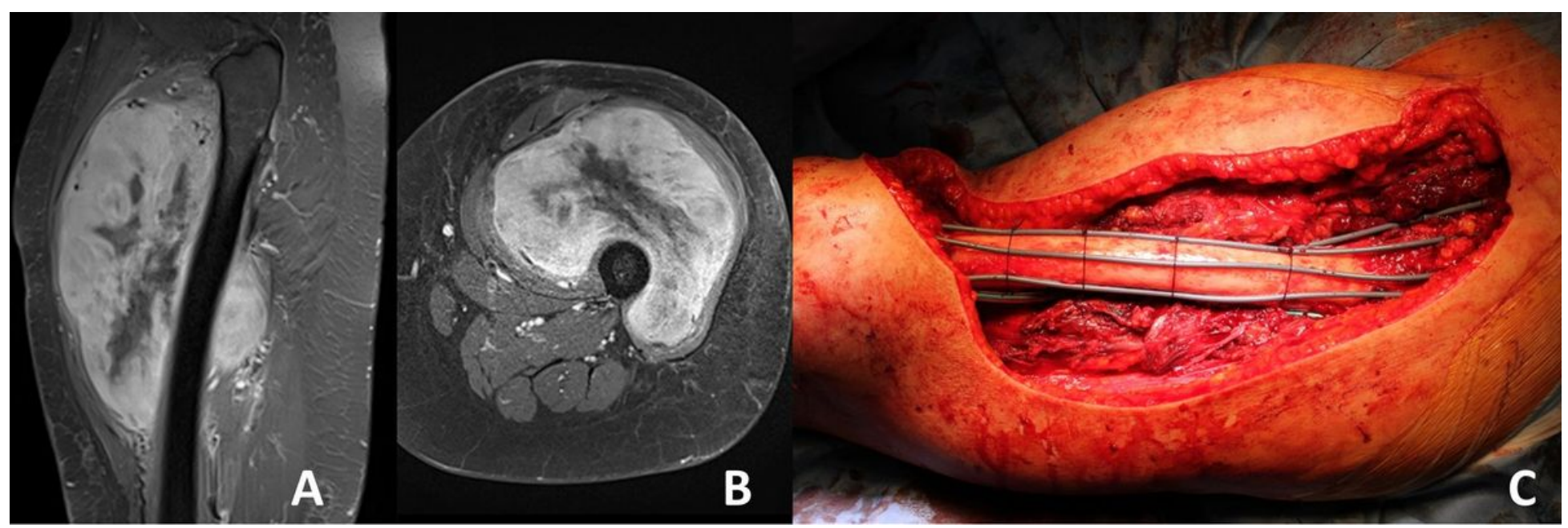

\section{Figure 1}

Patient with STS of the left thigh after preoperative (neoadjuvant) radiation (A-B). Brachytherapy catheter inserted (C). The patient developed an infected seroma that drained itself by breaking through the scar. In the clinical course the limb had to be amputated after 8 revision surgeries including 2 free flaps due to IWH.

\section{Supplementary Files}

This is a list of supplementary files associated with this preprint. Click to download.

- Coverletter.docx 